www. revis tad y o. com

\title{
Gestão da demanda: avaliação do processo em uma empresa de bens de consumo
}

\author{
Demand management: evaluation of the process in a consumer goods company
}

\author{
Mariana Aguiar Calixto, Andréia de Abreu y Rosane Lúcia Chicarelli Alcântara \\ Programa de Pós-Graduação em Engenharia de Produção. Universidade Federal de São Carlos - UFSCar. São Carlos/SP, Brasil.
}

mariana.a.calixto@gmail.com, andreiabreu11@gmail.com,rosane@dep.ufscar.br

Fecha de recepción: 03-02-2015

Fecha de aceptación: 21-10-2015

Resumo: Este artigo objetiva descrever o processo de gestão da demanda adotado por uma empresa multinacional de bens de consumo, com atuação no Brasil. A partir disto, desenvolver proposta de melhoria com base na realidade da empresa e nas diferenças entre os resultados encontrados e as indicações teóricas sobre o tema. Para tanto, utilizou-se o método de estudo de caso em um dos subsetores da referida empresa. Os resultados apontaram que o processo de gestão da demanda utilizado pela empresa é, de modo geral, um processo bem desenvolvido. No entanto, contatou-se a inexistência de um plano formal e sistematizado de contingências.

Palavras-chave: Gestão da demanda, Gestão da cadeia de suprimentos, Modelo de gestão da demanda, Empresa de bens de consumo, Mercado brasileiro.

\begin{abstract}
Due to new pattern of consumption arising by the change in the life style and the customer preferences, the companies need to be capable of offer a variety of products, customization and better services levels. However the market dynamic, effective for most business segments, is defined by the unpredictability and makes the effort of preview very critic. Among the strategies that are possible, the demand management has became as fundamental to the competitively. The purpose of this article is to describe the process of management demand that is adopted by a multinational consumer goods. This company also acts in Brazil. Due to this, the paper proposes suggestions for improvement that are based in the company reality and in the differences between the results which were founded and the theoretical indications about the topic. Therefore, it was used the case study method applied in a subsector of the company. The instruments of the research were interviews, documental analyses and direct observation. The results indicate that the process of management demand, which was used by the company is substantial and well-develop because helps in the achievement of objectives plotted as for the demand forecast and monitoring customer needs and desires. So there is a consistence between literature and practice about demand management that is adopted by the company. The dissonance point which was realized is the absence of a formal and systematized plan of contingency, then dissonance point is a step inside the management model of demand. It is concluded that the company understand the demand management as one of the process that compounds supply chain management. Though the stage "development of systems to contingency management" needs to be improved. The description of this successful process, performed by a large company, can serve as a reference guide for managers of companies that do not adopt the demand management or need to improve the existing.
\end{abstract}

Keywords: Demand management, Supply chain management, Demand management framework, Consumer goods company, Brazilian market.

\section{Introdução}

Nas últimas décadas o mercado tem passado por profundas transformações de ordem econômica, social, política e organizacional. A globalização é tida como a principal causa dessas transformações. Consequentemente, há o aumento da competitividade das empre- sas à medida que os consumidores têm fácil acesso aos produtos dos concorrentes internacionais (Stiglitz, 2003). Nesse contexto, é possível afirmar que as empresas, em número cada vez maior, estão disputando os mesmos clientes (Pires, 2009).

Mediante os desafios da competição nacional e internacional, particularmente em relação aos novos 
padrões de consumo decorrentes da mudança no estilo de vida e preferências do consumidor, as empresas precisam ser capazes de ofertarem variedade de produtos, customização e melhores níveis de serviços (Lee, 2002). Contudo, é preciso destacar que a dinâmica mercadológica, caracterizada por uma conjuntura de imprevisibilidade, torna o esforço de previsão bastante crítico (Sanders; Ritzman, 2004). Entre as possíveis estratégias, a gestão da demanda tem se configurado como fundamental para a competitividade.

A gestão da demanda é um tema emergente, advindo do campo de conhecimento da gestão da cadeia de suprimentos (Mentzer et al., 2001; Croxton et al., 2002) e do marketing (Juttner et al., 2007; Zokaei; Hines, 2007). Sua proposta central é o alinhamento entre a demanda e a capacidade operacional da cadeia de suprimentos, bem como a tradução, em produtos e serviços, dos desejos e necessidades dos consumidores (Melo; Alcantara, 2011). Autores como Walters e Rainbird (2004) e Christopher (2011) afirmam que a combinação entre a capacidade da cadeia de suprimentos e uma efetiva gestão da demanda permite à empresa posicionar-se melhor em valor aos clientes e explorar oportunidades de negócio.

Apesar do interesse crescente enquanto estratégia de gestão, ainda são poucos os estudos sobre a gestão da demanda (Adebanjo, 2009; Hilletofth, 2011). Segundo Pires (2009), a literatura emprega diferentes denominações, tais como "Gestão da Cadeia de Demanda" ou "Gestão da Demanda na Cadeia de Suprimentos" (Demand Chain Mangement - DCM), ou seja, há ausência de consenso. Além da dimensão teórica, há também a dimensão prática da necessidade de mais pesquisas sobre o tema: a falta de alinhamento entre oferta e demanda é um problema freqüente e oneroso em várias cadeias de suprimentos.

O alinhamento da demanda na cadeia de suprimentos enfrenta dificuldades progressivas, tais como falta de precisão nas informações, perdas devido a desperdícios, falta ou excesso de estoques. Como conseqüência, tem-se a ineficiência e ineficácia no atendimento a clientes, redução do giro de estoque e alto índice de obsolescência agravada pela grande diversidade de produtos são as conseqüências (Lau, 2012; Bustinza et al., 2013).

Portanto, é imperativo buscar uma definição mais clara deste processo de negócio, de suas principais atividades e desdobramentos, para assim entender como e onde a gestão da demanda se relaciona com os outros aspectos do modelo de gestão de uma empresa, tanto no seu âmbito interno quanto nas suas relações externas com a cadeia de suprimentos.
Tais fatos justificam o presente trabalho, cujo objetivo é descrever o processo de gestão da demanda adotado por uma empresa multinacional de bens de consumo, com atuação também no Brasil. A partir disso, propor sugestões de melhoria com base na realidade da empresa e nas diferenças entre os resultados encontrados e as indicações teóricas sobre o tema.

A questão de pesquisa a que se pretende responder com este estudo é: a empresa de bens de consumo estudada adota em seu negócio um método de gestão de demanda condizente com aquilo proposto pela literatura?

O artigo está estruturado em 5 seções, a contar dessa introdução. Na seção 2 apresenta-se a base teórica sobre gestão da cadeia de suprimentos e sua relação com a gestão da demanda, as abordagens para a gestão da demanda existentes da literatura, detalhando a abordagem escolhida como base para a pesquisa de campo. Na seção 3 descrevem-se os procedimentos metodológicos utilizados para o desenvolvimento do estudo de caso. Na seção 4 tem-se a descrição do processo de gestão da demanda analisado na empresa objeto de estudo e a análise das informações com a comparação entre teoria e prática, cuja diferença resulta na proposta de melhoria. Por fim, na seção 5 , estão as considerações finais compostas pela resposta ao problema de pesquisa, as contribuições e limitações da pesquisa e as sugestões para estudos futuros.

\section{Revisão da literatura}

\subsection{Gestão da cadeia de suprimentos e gestão da demanda}

Apesar de Cooper, Lambert e Pagh (1998) considerarem que o conceito de gestão da cadeia de suprimentos (SCM - Supply Chain Management) pode ser encontrado em teorias anteriores, esse assunto é considerado ainda recente e incipiente (Fabbe-Costes; Jahre, 2008; Daugherty, 2011). As discussões tiveram início a partir de estudos baseados em gestão de operações interorganizacionais, estudos de integração de sistemas (ambos originários na década de 1960) e os estudos da década de 1980 e 1990 sobre o papel do compartilhamento de informações de distribuição e inventário (Lambert; Cooper, 2000).

As modificações na dinâmica de mercado ocorridas com maior profundidade durante a década de 1990 impulsionaram aumento nas discussões sobre o tema. 
Em 1998, o Council of Logistics Management Professionals (CLMP) definiu que a cadeia de suprimentos é formada por várias empresas e os relacionamentos que ocorrem entre elas (Ballou, 2006; Lambert, 2008). Já para Christopher (2011), SCM é uma rede de organizações voltadas a produzir bens e serviços requeridos pelos clientes finais. Para o Council of Supply Chain Management Professional (CSCMP, 2012) a gestão da cadeia de suprimentos engloba o planejamento e a gestão de todas as atividades envolvidas com a aquisição e transformação de suprimentos e as atividades de gerenciamento logístico. Isso inclui coordenação e colaboração entre os membros da cadeia, sendo esses fornecedores, intermediários, provedores de serviços de terceira parte e clientes finais.

Mentzer et al. (2001) definem a gestão da cadeia de suprimentos como sendo a coordenação sistêmica e estratégica das funções operacionais e táticas de negócio internas e externas das empresas ao longo da cadeia de suprimentos, com o objetivo de melhorar os resultados de longo prazo da empresa individualmente e da cadeia de suprimentos como um todo. As principais funções organizacionais envolvidas são: logística, marketing, vendas, pesquisa e desenvolvimento, previsão, produção, compras, sistema de informação, finanças e serviços ao consumidor.

Para a Global Supply Chain Forum (GSCF), a gestão da cadeia de suprimentos significa a integração dos processos-chave de negócio desde o usuário final até o fornecedor original, provendo produtos, serviços e informações que agreguem valor aos clientes e outros stakeholders (Lambert et al., 2005). São oito os processos-chave de negócios propostos por esse modelo de SCM: Gestão do Relacionamento com Clientes, Gestão de Serviço ao Cliente, Gestão da Demanda, Processamento de Pedidos, Gestão do Fluxo de Manufatura, Gestão do Relacionamento com Fornecedor, Desenvolvimento do Produto e Comercialização, Gestão de Retorno (Lambert, 2008). Observa-se que a Gestão da Demanda é considerada um desses oito processos-chave, relacionando-se com o marketing, bem como os processos Gestão do Relacionamento com Clientes e Gestão de Serviço ao Cliente. No entanto, em função do propósito deste trabalho, os dois últimos não serão discutidos.

Para Lambert (2008), a gestão da demanda é o processo responsável por balancear as necessidades dos consumidores com a capacidade de suprimento de toda a cadeia. Para tanto, deve envolver as atividades de previsão, sincronização entre demanda e suprimentos, redução de variabilidade e aumento de flexibilidade. Pires (2009) afirma que a incerteza e as dificuldades em prever a demanda trazem impactos consideráveis à gestão da cadeia de suprimentos e, portanto, deve ser a primeira etapa desenvolvida para se obter uma cadeia de suprimentos efetiva.

Outra definição é apresentada por Rainbird (2004), que considera a gestão da demanda como sendo a compreensão das expectativas atuais e futuras dos clientes, das características do mercado e das alternativas disponíveis de respostas e a tradução disso, por parte das empresas, em processos operacionais. O assunto é considerado de tamanha importância que, para Christopher (2011), ao se considerar que as cadeias devem ser guiadas pelos consumidores e não pelos fornecedores, a gestão da cadeia de suprimentos poderia ser também denominada como "Gestão da Cadeia de Demanda".

Considerando as definições apresentadas, pressupõe-se que a gestão da demanda não pode ser considerada uma atividade resumida à previsão de vendas ou um processo isolado de uma função organizacional específica. A proposta é mais abrangente ao envolver a criação de sinergias entre a gestão de operação e de marketing, com objetivo de compreender o mercado e desenvolver ações sincronizadas entre opções estratégias e capacidade produtiva das empresas na cadeia de suprimentos (Hilletofth, 2011; Lau, 2012; Bustinza et al., 2013).

Porém, apesar do papel reconhecido para a competitividade da cadeia de suprimentos, a gestão da demanda não é bem compreendida pelos seus membros (Mentzer; Moon, 2004; Pires, 2009). Estudos empíricos demonstram haver muitas dificuldades no alinhamento entre as previsões do marketing (ao determinar o que, onde e como vender) e as demais áreas funcionais da empresa em executá-las (Juttner et al., 2007; Ellinger et al., 2012). Assim, seja como parte da SCM ou como um novo conceito de gerenciamento, a temática precisa ser mais bem estudada e compreendida.

\subsection{Abordagens para a gestão da demanda}

Antes da adoção de qualquer abordagem para a gestão da demanda é necessário que a empresa tenha conhecimento exato das características da sua demanda. Tipologias de demanda foram propostas por Fischer (1997), Lee (2002) e Bowersox et al. (2007), cuja compreensão pode evitar erros comuns e suas conseqüências, desde a previsão até a tradução das 
necessidades dos clientes em estratégias operacionais.

Melo e Alcântara (2011) realizaram um estudo de levantamento das abordagens para a gestão da demanda existentes na literatura, classificando-as em dois blocos: (a) gestão da demanda como a integração da gestão de marketing e suprimentos (Juttner et al., 2007; Esper et al., 2010; Hilletofth et al., 2009; Voluntary Interindustry Commerce Standards, 2010) e (b) gestão da demanda como um processo ou componente da SCM (Mentzer; Moon, 2005; Croxton et al., 2008).
Dentre as abordagens, apenas Croxton et al. (2008) delineiam o processo de gestão da demanda a partir dos outros sete processos-chave da SCM, anteriormente mencionados, destacando os seus subprocessos operacionais e estratégicos e a inter-relação entre eles. $O$ objetivo central é o equilíbrio entre as exigências dos clientes e a capacidade da cadeia de suprimentos via previsão de vendas, sincronização da capacidade produtiva da empresa e da cadeia, incorporação da estratégia da organização e mapeamento das necessidades dos clientes. Por essa razão, esse é o modelo escolhido como parâmetro para a pesquisa de campo deste trabalho. A Figura 1 apresenta o modelo proposto pelos autores.

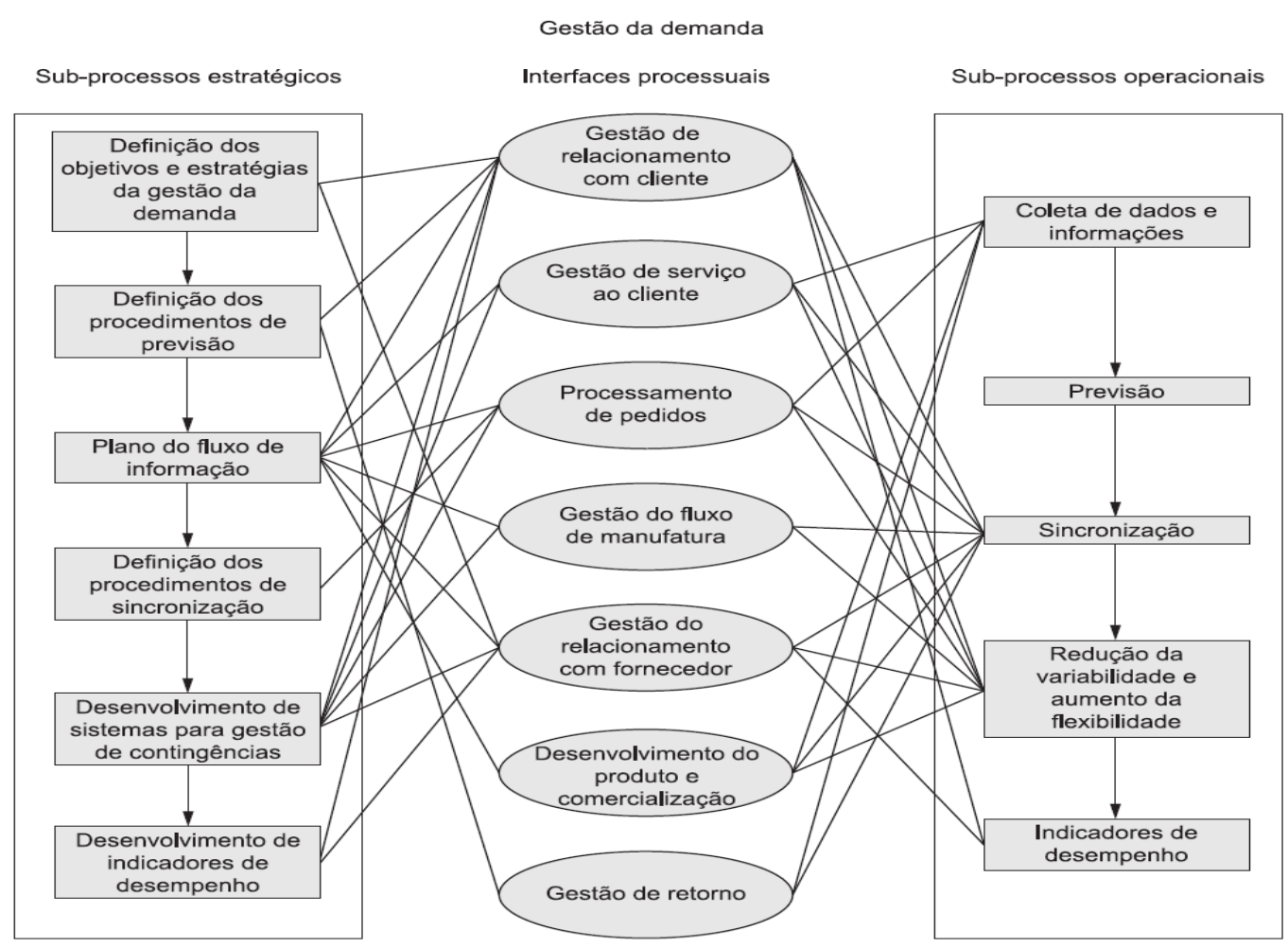

Figura 1 - Modelo de gestão da demanda

Fonte - Croxton et al. (2008, p.89)

Para sua efetivação, propõe-se uma estrutura de equipe de trabalho multifuncional, podendo ou não incluir membros externos à empresa, composta por gerentes das diferentes áreas funcionais, como: marketing, finanças, produção, compras e logística. Essa equipe deve ser responsável por liderar os processos operacionais e os estratégicos. Nos campo estratégico, é responsável por desenvolver procedimentos e garantir sua implementação. Já no campo operacional a responsabilidade é assegurar, por meia da execução das atividades rotineiras, que os processos sejam realizados conforme o planejado. A definição dos procedimentos para elaboração da previsão também deve ser realizada pela equipe operacional (Croxton et al., 2008).

Para cada um dos subprocessos (estratégicos e operacionais) os autores prevêem um conjunto de atividades a serem desenvolvidas e as interfaces com outros sete processos-chave da gestão da cadeia de suprimentos (Figura 1) propostos pelo GSCF (Lambert et al., 2005). Conforme mencionado, os subprocessos estratégicos são estabelecidos a fim de desenhar um sistema operacional eficiente em equiparar a demanda com os suprimentos. O conjunto de atividades de cada um deles são: 
- $\quad$ Definição dos objetivos e estratégias da gestão da demanda: previsão das estratégias da empresa, estudo da rede de fornecimento e gargalos, definição de foco e objetivos do processo;

- Definição dos procedimentos de previsão: definição dos níveis de previsão, definição das fontes de dados, análise de diferentes enfoques (VMI - Vendor Managed Inventory, CPFR - Collaborative Planning, Forecasting and Replenishment, tradicional), escolha de métodos apropriados e plano de previsão;

- $\quad$ Plano de fluxo de informação: definição das necessidades de dados, definição das fontes de dados e sua importância, definição de como as informações serão compartilhadas, influência das informações na formulação da estratégia de negócios;

- Definição dos procedimentos de sincronização: delineamento dos procedimentos de sincronização, definição das necessidades de planejamento de longo prazo, análise das capacidades de manufatura/fornecedores, definição de procedimentos de alocação;

- Desenvolvimento de sistemas para gestão de contingências: definição de potenciais interrupções no fornecimento, definição de respostas a cada possível evento;

- Desenvolvimento de indicadores de desempenho: ligação entre o desempenho da gestão da demanda e o EVA (Economic Value Added), definição dos indicadores e o conjunto de objetivos.

Orientados pelas decisões tomadas no nível estratégi$\mathrm{co}$, os subprocessos operacionais se encarregam de executar tais diretrizes, focando sempre em reduzir a variabilidade e aumentar a flexibilidade. O conjunto de atividades de cada um deles são (CROXTON et al., 2008):

- $\quad$ Coleta de dados e informações: coleta de dados históricos da demanda, coleta de informações de marketing e vendas, coleta de informações sobre os clientes (VMI, CPFR);

- Previsão: análise de dados, desenvolvimento de previsão, monitoria de erros e fornecimento de feedback;

- $\quad$ Sincronização: identificação e planejamento a partir das restrições de capacidade, definição dos intervalos de previsão, desenvolvimento de planejamento agregado da demanda, balanceamento de riscos a partir de restrições financeiras, planejamento de capacidade para novos produtos;
- Redução da variabilidade e aumento da flexibilidade: identificação das causas- raiz da variabilidade, ações para redução da variabilidade da demanda dentro da empresa e da cadeia de suprimentos, definição dos níveis de flexibilidade necessários, identificação das oportunidades para aumento da flexibilidade, ações para aumentar a flexibilidade da demanda dentro da empresa e da cadeia de suprimentos;

- Indicadores de desempenho: cálculo dos indicadores de desempenho do processo, conexão entre os indicadores de desempenho e o EVA.

A principal contribuição desse modelo está na visão inter-relacional e sistêmica da gestão da demanda. Enfim, Croxton et al. (2008) defendem que a implantação bem conduzida do processo pode gerar benefícios substanciais para os resultados financeiros da empresa pela redução dos níveis de estoque, melhoria na utilização dos ativos e melhoria na disponibilidade do produto final.

\section{Método de pesquisa}

Para atender ao objetivo proposto e responder à questão de pesquisa foi escolhida uma abordagem qualitativa, desenvolvida por meio do método de estudo de caso e seguindo o paradigma fenomenológico. Esse último, por este trabalho não recorrer à aplicação de testes de hipótese, de controle de variáveis e de análises estatísticas de correlação entre variáveis. Segundo Seuring (2005), o método de estudo de caso é bastante apropriado para pesquisas no âmbito da gestão da cadeia de suprimentos pela flexibilidade na coleta de informações.

Considerando que os resultados visam comparar problemas reais com modelos teóricos, este trabalho pode ser classificado como uma pesquisa aplicada (Strauss; Corbin, 2008). Quanto ao objetivo, é descritiva em virtude da natureza dos fenômenos, do tipo de relação e da necessidade de descrever suas especificidades. Para Gil (2010), as pesquisas descritivas descrevem características de determinada população ou fenômeno.

O método de estudo de caso foi considerado o mais apropriado para este trabalho por envolver uma análise de natureza empírica, investigando um determinado fenômeno dentro de um contexto real e ainda pouco estudado pela literatura (Voss, 2009). No caso, o processo de gestão de demanda adotado por uma empresa industrial produtora de bens de consumo. 
A empresa objeto de estudo é uma multinacional, com mais de 300 marcas comercializadas em 140 países, sendo 50 delas globais e líderes de mercado. Com sede nos Estados Unidos, está presente no Brasil há mais de 20 anos com, aproximadamente, 30 marcas em 17 diferentes categorias de produtos. O escritório administrativo da companhia está localizado na cidade de São Paulo e há plantas produtoras nos estados de São Paulo, Amazonas, Rio de Janeiro e Bahia. Os centros de distribuição estão dispersos em cidades dos estados de Alagoas, Rio de Janeiro, Goiás e Minas Gerais. Dentre seus clientes, estão todas as grandes redes varejistas e atacadistas atuantes no país e as principais redes de drogarias.

A coleta dos dados e informações foi realizada pessoalmente e in loco em uma das unidades produtoras localizada no estado de São Paulo, durante o segundo semestre de 2012. Os instrumentos de coleta foram entrevistas, observação passiva e análise documental, cujas análises permitiram conhecer o processo de gestão da demanda adotado pela empresa, bem como detectar suas falhas e oportunidades de melhoria. É válido destacar a receptividade e o interesse dos integrantes da empresa em fornecer as informações necessárias para a realização da pesquisa.

Para as entrevistas foram utilizados questionários semi-estruturados, aplicados aos supervisores e gerentes participantes do processo de gestão da demanda do subsetor "Cuidados com a Casa", composta por três categorias de produtos aqui denominadas como $\mathrm{A}$, $\mathrm{B}$ e C. Todas as entrevistas foram realizadas durante o mês de novembro de 2012, em sessões diferentes.

As observações passivas ocorreram com a presença em reuniões nas quais a gestão da demanda era pauta, e no acompanhamento de treinamentos, procurando identificar o processo empregado pela empresa. As reuniões mais importantes para o propósito deste trabalho foram as de Processo Operacional de Negócio (PON), realizadas todo início de mês e onde são tomadas várias decisões de negócio. Nelas, participam membros dos departamentos de finanças, vendas, marketing e logística. Foram observados e registrados os assuntos discutidos, o fluxo de informações e o comportamento de todos os participantes.

Uma das sessões de trabalho e discussões da equipe de logística sobre a gestão da demanda também foi observada. Ocorrem em média a cada 3 meses e são ministradas pelo Gerente de Grupo, responsável pela implementação do processo PON no Brasil. Já a análise documental ocorreu com o acesso posterior aos relatórios e registros em arquivos das referidas reuniões, bem como de outras realizadas anteriormente ao período da investigação.
A próxima seção tratará da apresentação e discussão dos resultados obtidos com a análise dados e informações obtidos nesses levantamentos.

\section{Resultados}

\subsection{Apresentação geral}

Em função do acesso permitido pela empresa para a realização da pesquisa, será analisada a gestão da demanda do subsetor "Cuidados com a Casa", responsável pelas três categorias de produtos mencionadas. A estrutura hierárquica é composta por um Gerente de Área e cada categoria é supervisionada por um Supervisor Júnior. Há também um funcionário para cuidar, exclusivamente, do processo operacional de abastecimento de produtos de cada uma das categorias, diretamente subordinado ao Gerente de Área.

A categoria A é a segunda maior em vendas na empresa, representada por três diferentes marcas de fabricação nacional, com produtos de baixo valor agregado e baixa margem de lucro. Por se tratar de um setor instável, a categoria busca lançar novos produtos no mercado seguindo as tendências de compra dos consumidores. A categoria B é representada por apenas uma marca, porém líder de mercado no país há mais de uma década, com produtos de alto valor agregado e alta margem de lucro. Busca diferenciação via ações de marketing. Todos os produtos da categoria são importados, principalmente da China e dos Estados Unidos. Já a categoria $C$, também representada por uma única marca e com produtos importados, é nova no país: lançada em 2011. Apesar de ser uma das marcas mais valiosas da empresa no exterior, é a menor categoria no Brasil. Por isso, o acompanhamento das ações da concorrência e do mercado em geral nessa categoria é constante por parte da empresa.

Faz parte da cultura da empresa trabalhar com estrutura organizacional mista: funcional, para a execução das atividades operacionais e, matricial, para a execução de projetos e gestão de processos de negócio. Na funcional, os funcionários são formalmente alocados em uma das áreas funcionais, sendo essas: Engenharia e Manufatura, Vendas, Marketing, Inteligência de Mercado, Finanças, Logística, Recursos Humanos, Tecnologia da Informação, Relações Externas, Jurídico, Compras, Pesquisa e Desenvolvimento. Na matricial, parte desses funcionários é alocada a grupos multifuncionais voltados à gestão de determinados clientes e categorias de produtos. 
A estrutura matricial é empregada para o processo de gestão da demanda nesse subsetor. Cada uma das três categorias é liderada por um grupo multifuncional (Figura 2) com integrantes dos departamentos de Marketing, Logística, Vendas, Finanças e Inteligência de Mercado, sendo todos suportados pelo departamento de Tecnologia da Informação. A gestão da demanda é realizada por esses grupos, cujo número de integrantes varia de acordo com a complexidade do negócio no momento.

\section{Time Multifuncional}

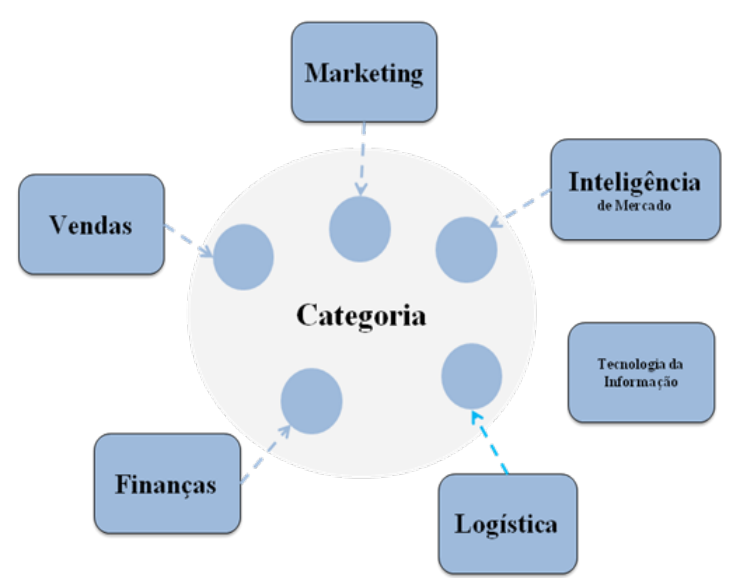

Figura 2 - Grupo multifuncional com foco em uma categoria Fonte - elaborado pelas autoras

O time de Marketing tem como função promover as marcas da categoria, perceber a oportunidade de novos produtos, desenvolver promoções e produtos especiais para clientes, compartilhar dados do mercado, acompanhar a concorrência e, juntamente com Finanças, gerenciar os recursos financeiros da categoria. O time de Vendas se responsabiliza não apenas pelas vendas efetivas dos produtos, mas também pela execução de planos de venda com clientes específicos ao longo dos meses, auxiliando no alcance das metas de vendas pré-estipuladas e realizando a interface entre a empresa e seus clientes. O time de Finanças é o responsável por gerenciar o recurso financeiro das demais categorias do time, posto haver um orçamento a ser seguido durante o ano fiscal da empresa. É também responsável por relacionar a margem de lucro de cada cliente com seu volume estimado para venda.

A liderança do processo de gestão de demanda é realizada pelo time de Logística. Por isso, conduz todas as reuniões atreladas ao processo e determina a previsão de vendas a curto e médio prazo, tendo como base as informações geradas pelos demais times do grupo multifuncional. Realiza a interligação entre as fábricas que produzem os produtos da categoria, seu grupo multifuncional e o mercado. Todas as informações de capacidade de suprimentos são passadas para esse time.

O time de Inteligência de Mercado fornece dados de mercado para todo o grupo, provendo-o com informações sobre as tendências dos setores e ambiente geral do negócio em um horizonte maior de tempo. Já o time de Tecnologia da Informação não participa diretamente do grupo. Seu papel é fornecer suporte tecnológico (hardware e software) e informacional aos times e categorias de produtos.

\subsubsection{Descrição do processo de gestão da demanda adotado pela empresa}

Esta subseção visa descrever o processo de gestão da demanda adotado pela empresa em estudo, tendo como base o modelo de gestão da demanda proposto por Croxton et al. (2008). Portanto, são apresentadas as atividades desenvolvidas nos processos estratégico e operacional do referido modelo para, posteriormente, serem identificadas as semelhanças e divergências.

\section{(1) Definições dos objetivos e estratégias da demanda:}

A estratégia geral da empresa, determinada a partir da estratégia global da matriz, é o principal guia de trabalho dos grupos multifuncionais: dela são desenhadas as ações para se atingir as metas. A estratégia está diretamente relacionada com a capacidade de manufatura de seus produtos, bem como a capacidade dos fornecedores, servindo de base para a determinação da demanda de cada produto.

A categoria A é a mais influenciada pelas estratégias de crescimento da empresa no Brasil, em função da sua necessidade de maior volume de vendas (baixo valor agregado e baixa margem de lucro) e, por isso, busca metas arrojadas. A categoria $B$ segue as estratégias de negócio ditadas pela central da América Latina, não tão agressivas quanto as metas da categoria $A$. Já a categoria $C$ alega ainda não ter atingido as metas de lançamento da marca, ocorrida em 2011. Pelas entrevistas foi possível notar que as três categorias se relacionam constantemente com os outros departamentos da empresa.

\section{(2) Definição dos processos de revisão:}

A previsão de vendas para cada categoria é realizada no mês de abril, abrangendo o próximo ano fiscal. Para tal, os grupos multifuncionais se reúnem diversas vezes para definir a projeção de demanda oficial, utilizando-se o nível de vendas do ano anterior e acrescentando as previsões de mercado do setor o qual a 
empresa pertence. Considera-se também se haverá lançamentos de novos produtos, promoções, aumento ou reduções de preços. O número final é decidido em conjunto, por todos os integrantes dos grupos. As três categorias seguem a mesma sistemática de análise.

\section{(3) Plano do fluxo de informação:}

A previsão de demanda é criada considerando os dados de entrada dos integrantes dos grupos multifuncionais e demais áreas da empresa. A interface maior ocorre com o departamento de Vendas, sendo captados os dados de inventário no cliente, dados de vendas para os clientes e do cliente para o consumidor final, expectativa de vendas futuras, datas de faturamento dos pedidos, datas estimada de recebimento do pedido. Outra importante informação fornecida é o nível de satisfação dos clientes. Há também interfaces com o departamento financeiro e de produção. Diariamente, são cruzadas as informações de pedidos dos clientes, volume de inventário e capacidade de produção.

\section{(4) Definição de procedimentos de sincronização:}

Para a sincronização no gerenciamento da demanda, a empresa segue o procedimento conhecido como Processo Operacional de Negócio (PON), implementado visando adaptar o processo de Vendas e Planejamento das Operações (S\&OP - Sales and Operations Plannning). O PON ocorre em ciclo mensal e exibe informações tanto em quantidade quanto em valor monetário para assim integrar o planejamento financeiro $\mathrm{e}$ operacional e, com isso, atender a demanda com precisão.

O processo se baseia em cinco etapas principais, representados na Figura 3:

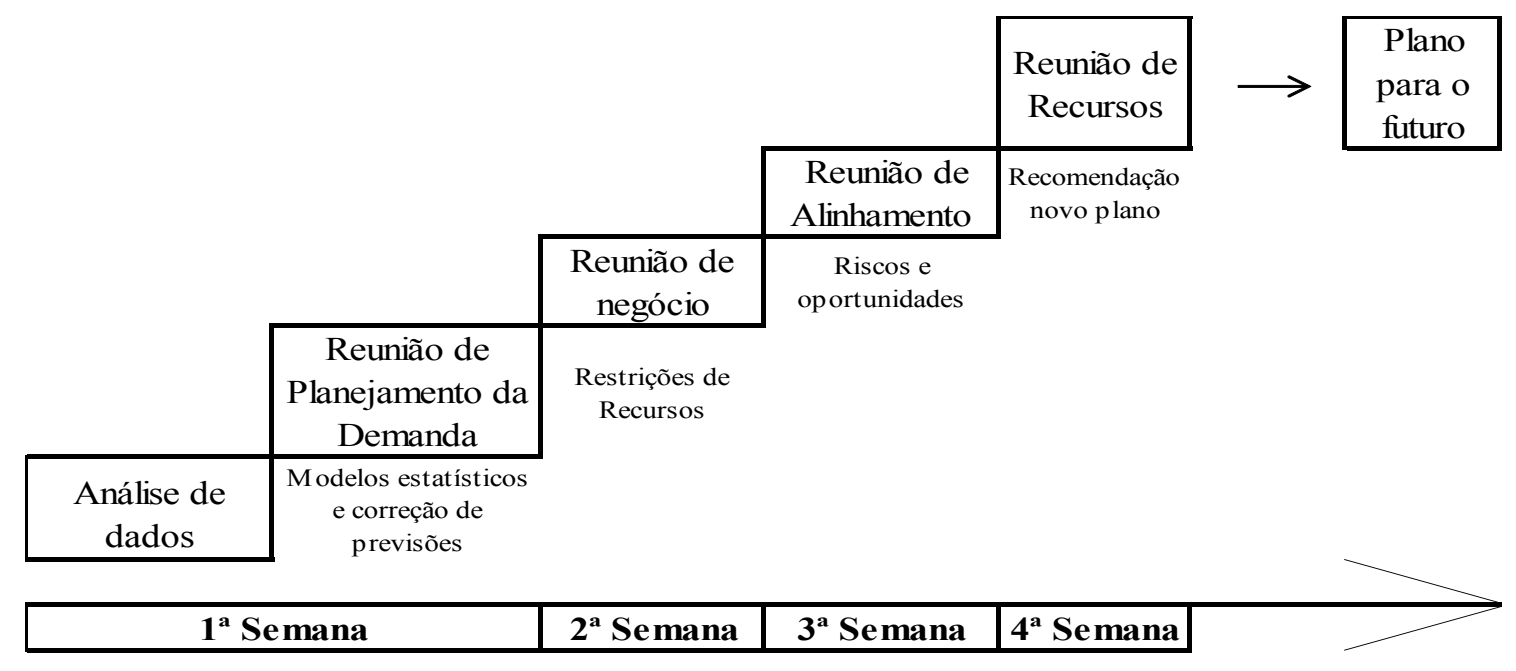

Figura 3 - Processo PON executado pela empresa

Fonte - elaborado pelas autoras

1. Análise de dados: todo começo de mês o supervisor de demanda de cada categoria capta e analisa os dados referentes a inventário de seus produtos nos clientes, total de vendas nos canais de mercado, total de vendas nos clientes finais e compila dados sobre $o$ mês anterior. Os resultados servem de entrada para a próxima etapa do processo;

2. Reunião de planejamento da demanda: ocorre na primeira semana de cada mês e é liderada pelo supervisor da demanda de cada categoria e pelo encarregado de finanças da mesma. Participam todos os integrantes do grupo multifuncional da categoria e o diretor de marketing da empresa. Visa prover uma visão global do negócio da categoria e planejar ações futuras para os próximos meses, como redução de volume, preços, entre outras. Para as análises das projeções são utilizados modelos estatísticos. Ao final, o departamento de produção é consultado sobre a capacidade de fabricação para a demanda estimada;

3. Reunião de negócio: ocorre entre a segunda e terceira semana do mês, objetivando identificar se há obstáculos no mês corrente que inviabilizariam o alcance da meta prevista. Conta com presença de representantes dos departamentos de suprimentos, marketing, vendas e finanças. Resulta em planos de correção para o mês atual e perspectivas para os próximos meses; 
4. Reunião de alinhamento: ocorre na terceira semana do mês, sendo liderada pelos representantes da área de finanças juntamente com representantes da central da América Latina, com o propósito de monitorar o andamento da empresa no país. Participam representantes das áreas de finanças, marketing e suprimentos. Discute-se sobre o andamento do mês em termos de volume e receita, bem como as expectativas de fechamento do mesmo em comparação à meta geral estipulada no mês de abril. Além disto, os riscos e oportunidades apontados na reunião anterior são também debatidos;

5. Reunião de recursos: realizada no final do mês corrente, visando a determinação de planos para médio prazo. Há também a participação dos representantes da central na América Latina. São estudadas possibilidades de ampliação da capacidade produtiva das unidades, planos para lançamento de novos produtos e evolução do mercado. Os planos vigentes são revisados, considerando acompanhar o planejado com o alcançado até então. Supostamente, todas as categorias deveriam seguir o PON rigidamente, já que se trata de um processo unificado. Porém, foi verificado que nem todas o aplicam em seus procedimentos de gestão. Colabora para isso o fato das categorias serem diferentes entre elas no que diz respeito a características, situação de mercado e, consequentemente, prioridades. Ademais, é comum a falta de entendimento entre as áreas, resultando em algumas imposições finais.

(5) Desenvolvimento de sistemas para gestão de contingências:

A empresa não possui planos de contingência documentados. Os riscos do negócio são discutidos em duas das etapas do processo PON e, somente a partir disso, os planos de ações são desenvolvidos para eliminar os resultados não desejados. Cada categoria trabalha com um nível de estoque de segurança de seus produtos, dependendo da flexibilidade de produção e do lead time de entrega. Isso ajuda a suprir a demanda das fábricas caso haja problemas com o fornecedores ou oscilação da demanda estimada. Quando algum problema de fato ocorre, o mesmo é gerenciado diretamente com o cliente.

(6) Desenvolvimento de indicadores de desempenho:

Há no subsetor em análise (Cuidados com a Casa) um grupo de trabalho designado como Capabilities, responsável por gerenciar as medidas de desempenho das categorias A, B e C. São as medidas: (a) nível de inventário, compartilhada na primeira e última semana de cada mês; (b) volume entregue aos clientes versus volume encomendado, divulgada todo início de mês e com meta de $98 \%$; (c) inventário não produtivo, consideradas as mercadorias próximas do prazo de validade, com meta de $2 \%$. Relatórios diários são gerados por todas as categorias, apresentando o volume vendido e o valor financeiro obtido a fim de obter a acuracidade da previsão de demanda e a medida geral de desempenho.

(7) Desenvolvimento de redução da variabilidade e aumento da flexibilidade:

Conforme mencionado, cada categoria tem um nível de flexibilidade de produção, dependendo se o produto é importado (categorias $B$ e C) ou produzido em território nacional (categoria A). Em geral, os importados possuem três meses de estoque de segurança nos centros de distribuição e, os nacionais, são determinados de acordo com o nível de demanda dos diferentes clientes da empresa. A variabilidade da demanda pode ser reduzida com o entendimento entre as áreas componentes das equipes funcionais e demais da empresa via discussões durante o processo de PON.

\subsection{Análise comparativa e proposta de melhoria}

Comparando-se o processo de Gestão da Demanda da empresa em estudo com o modelo de gestão da demanda proposto por Croxton et al. (2008) verificou-se compatibilidade entre a literatura e a prática de gestão da demanda realizada pela empresa.

Apesar das três categorias de produtos cumprirem o modelo proposto por Croxton et al. (2008), foi possível notar diferenças no modo como as etapas do modelo são gerenciadas em termos de profundidade de análises, duração das reuniões de discussão e formação dos grupos multifuncionais. A justificativa está nas características e complexidade do negócio de cada categoria, diferentes entre elas.

A categoria $C$, por ser a menor dentre as três, com um volume de vendas relativamente pequeno para a empresa e ainda em fase de consolidação no mercado, recebe menos enfoque na gestão da demanda. Assim, segue o processo de maneira mais superficial.

Por ter alto volume de produção e vendas, mas também grande concorrência e, por isso, precisa constantemente inovar, a categoria A é a que desenvolve o processo com maior profundidade. Busca a excelência na previsão a demanda, captando as exigências e mutações do seu mercado. Reconhece que o processo de gestão da demanda é o modo mais eficiente para 
manter os produtos da categoria em crescimento de market-share.

Já a categoria B é intermediária entre os dois últimos casos, também seguindo o processo de gestão da demanda, mas sem necessidade de aprofundamento nas discussões como na categoria A. Isso se dá por ser uma categoria consolidada, com domínio do mercado em que atua. Porém, pelo volume de vendas ser representativo para a empresa financeiramente, entende que o comportamento da demanda não pode ser negligenciado.

Interessante ressaltar a constatação de que a área funcional com maior responsabilidade na gestão da demanda é a logística, sendo inclusive o time de trabalho líder dos grupos funcionais, seguida do marketing. $\mathrm{Na}$ empresa, o departamento de logística tem a prerrogativa de administrar o fluxo de produtos acabados das plantas produtoras aos clientes e distribuidores, cuidando da armazenagem, transporte e projeção de demanda de produto acabado, desde o volume estimado até sua disponibilidade nas prateleiras. De modo mais específico, duas funções da área se destacam na gestão da demanda:

1) Customização: responsável pelo desenvolvimento de produtos diferenciados, atendendo necessidades especiais dos clientes, alavancando as vendas de produtos já existentes ou mesmo ajudando na experimentação de novos produtos. Desenvolvimento do item promocional, produção e gerenciamento de inventário são outras das suas responsabilidades;

2) Demanda e Abastecimento: responsável pela previsão de demanda a médio e curto prazo dos produtos a serem comercializados por meio do PON (Processo Operacional de Negócios), utilizando os dados históricos, prevendo novas iniciativas e eventos nos clientes. Analisa a capacidade das plantas produtoras e garante a entrega dos pedidos.

Pela inter-relação entre as áreas funcionais, formação de grupos multifuncionais, cumprimento das etapas seqüências, sintonia com o mercado e estratégias de gestão adaptadas aos requisitos das categorias de produtos, conclui-se que a empresa entende a gestão da demanda como um dos processos componentes da gestão da cadeia de suprimentos.

O ponto de dissonância percebido entre a teoria e a prática realizada pela empresa é a inexistência de um plano formal e sistematizado de contingências, sendo esta uma entre as etapas do modelo de gestão da demanda referência nessa pesquisa. Conforme os entrevistados, os eventos inesperados interferem diretamente na atuação da empresa, resultando em elevação dos custos e perda de vendas.

A Gestão de Riscos em cadeias de suprimentos é tema crescente de discussões e estudos. Isso porque, conforme apontam Zsidisin et al. (2004), riscos existem na obtenção bens e serviços pelas empresas e, por conseguinte, devem ser assumidos a fim de garantir ao máximo o bom funcionamento dos processos internos. Entre esses processos, pode-se incluir a gestão da demanda.

Diante desse contexto, propõe-se então um processo híbrido para a gestão de risco a fim de melhorar a etapa "desenvolvimento de sistemas para gestão de contingências" do processo de gestão da demanda utilizado pela empresa, com base nas propostas teóricas dos autores Zsidisin et al. (2004) e Viswanadham e Gaonkar (2008). A Figura 4 ilustra o processo proposto: 


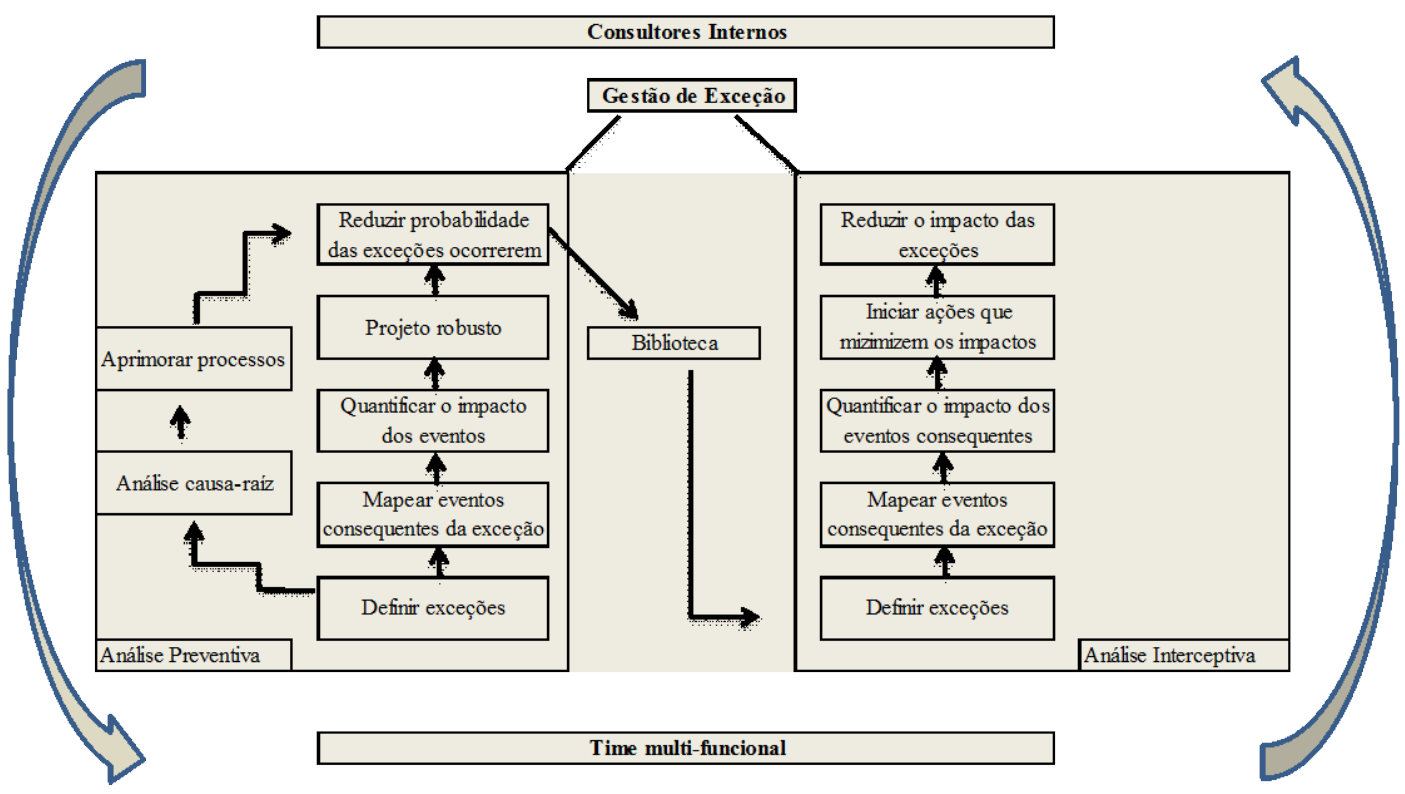

Figura 4 - Proposta de um processo para a gestão de risco da empresa

Fonte: elaborado pelas autoras, com base em Zsidisin et al. (2004) e Viswanadham e Gaonkar (2008)

Como a empresa não possui procedimentos para gestão de contingências, a primeira iniciativa consistiria em mapear os eventos inesperados já ocorridos em todas as categorias, conforme a ideia de Análise Preventiva proposta por Viswanadham e Gaonkar (2008). Para tanto, seria formado um time multifuncional, como indicado por Zsidisin et al. (2004), com representantes das áreas de Vendas, Finanças, Marketing e Logística, cuja função é realizar as análises específicas de causa-raíz dos eventos ocorridos e suas conseqüências na cadeia de suprimentos. A partir dessas informações, se desenvolveria um projeto robusto voltado à prevenção de ocorrência desses e outros possíveis eventos.

Uma vez que o projeto robusto estaria pronto e validado pelos gerentes imediatos das áreas funcionais do time multifuncional, o mesmo deveria ser armazenado em uma biblioteca virtual e disponibilizado para consulta. Esse também seria um espaço de compartilhamento de experiências e sugestões de melhorias para que, conjuntamente, novos planos de ações preventivos ou até mesmo reativos pudessem ser continuamente realizados.

Nesse último caso, ou seja, para análise interceptiva, os dados da biblioteca virtual serviriam como benchmarking, onde conhecimento acumulado na correção de eventos inesperados passados poderia ser utilizado no evento inesperado presente. Caso positivo, adaptálo para a eliminação da exceção. Caso negativo, tra- balhar no problema de forma aprofundada, seguindo todas as etapas citadas por Viswanadham e Gaonkar (2008) a fim de garantir acurácia e rapidez no processo.

Outro ponto importante a ser introduzido para a gestão de risco da empresa é a consultoria interna, proposta por Zsidisin et al. (2004). A empresa já possui inúmeros treinamentos globais que abrangem vários temas importantes para o negócio, mas nenhum com esse enfoque. Portanto, a proposta é montar um time multifuncional com gerentes e/ou diretores com alguma experiência em gestão de situações adversas e não programadas, com a responsabilidade de promover treinamentos periódicos aos demais membros da empresa ligados a atividades que necessitam de planos contingenciais. O conteúdo contemplaria o compartilhamento de experiências, bem como o ensino de técnicas qualitativas e quantitativas para a tomada de decisões de risco, análise de cenário, entre outras.

\section{Considerações finais}

O objetivo deste trabalho foi descrever o processo de gestão da demanda adotado por uma empresa multinacional de bens de consumo e, a partir da sua análise, propor sugestões de melhoria com base nas indicações teóricas sobre o tema. Entre os modelos de gestão da demanda existentes na literatura, levantados por meio da revisão bibliográfica, optou-se pelo 
modelo de Croxton et al. (2008) como roteiro para o levantamento dos dados na pesquisa de campo, apresentação dos resultados e comparação.

Por meio do estudo de caso foram analisadas três categorias de produtos, ligadas ao subsetor "Cuidados com a Casa". Verificou-se que o processo de gestão da demanda utilizado nessa linha de produtos é, de modo geral, um processo robusto e bem desenvolvido, auxiliando no alcance dos objetivos traçados quanto à previsão de demanda e acompanhamento dos desejos e necessidades dos clientes. Há, portanto, compatibilidade entre a literatura e a prática de gestão da demanda realizada pela empresa.

Ficou evidente a consciência da alta administração da necessidade em gerenciar a demanda dentro dos parâmetros atuais de competitividade, concorrência e padrões de consumo. Isso se reflete nos planos táticos e operacionais, convertendo-se em atitudes de gestão que vão além da mera execução de atividades rotineiras e operacionais. Como exemplo, tem-se o uso de estrutura matricial para a formação de grupos de trabalho multifuncionais, corroborando com as indicações teóricas sobre o formato organizacional adequado para a gestão da demanda em cadeias de suprimentos. Enfim, essas constatações respondem à questão de pesquisa proposta neste trabalho.

O estudo ter sido realizado em apenas um subsetor da empresa caracteriza uma limitação. Desse fato emerge uma indicação de pesquisa futura: estudar a gestão da demanda na visão dos outros elos da cadeia de suprimentos a qual a empresa pertence, percebendo com isso se há congruência de métodos e sincronia na troca de informações. Os resultados poderiam auxiliar na melhora do inter-relacionamento externo. Esse enfoque é ainda mais preponderante mediante o fato da empresa depender de intermediários a jusante (distribuidores, atacadistas e varejistas) para seus produtos chegarem até o consumidor final.

Espera-se que a revisão de literatura apresentada e os resultados do estudo de caso possam contribuir para uma melhor compreensão da gestão da demanda em cadeias de suprimentos, principalmente pelo fato de ser um tema ainda pouco explorado em estudos teórico-empíricos. Em termos práticos, a descrição de um processo de gestão da demanda bem-sucedido, realizado por uma grande empresa, pode servir como guia de referência aos gestores de empresas que não realizam a gestão da demanda ou que precisam aprimorar a existente. Mais pontualmente, as constatações podem também contribuir para a empresa analisada, ao indicar os problemas e pontos de melhoria no processo que vem sendo empregado.
Sob a perspectiva teórica, essa pesquisa contribui para a literatura ao comparar um modelo teórico de gestão da demanda bastante referenciado nos estudos acadêmicos com a prática de uma empresa multinacional de grande porte, demonstrando a existência de uma aplicação real e os benefícios oriundos dela, conforme asseguram as indicações teóricas sobre o tema. Dessa forma, ao ser analisada uma unidade brasileira, espera-se que este artigo possa estimular o desenvolvimento de mais estudos sobre o tema no contexto brasileiro, principalmente pelo fato da dinâmica das cadeias de suprimentos e os padrões de consumo diferirem significativamente entre os mercados.

\section{Referências}

ADEBANJO, D. (2009). "Understanding demand management challenges in intermediary food trading: a case study". Supply Chain Management, 14 (3), pp. 224-233.

BALLOU, R. H. (2006). "The evolution and future of logistics and supply chain management". Produção, 16 (3), pp. 375-386.

BOWERSOX, D. J., CLOSS, D. J., e COOPER, M. B. (2007). Gestão da cadeia de suprimentos e logística, 2 ed, Rio de Janeiro: Campus.

BUSTINZA, O. F., PARRY, G. C., y VENDRELL-HERRERO, F. (2013). "Supply and demand chain management: the effect of adding services to product offerings". Supply Chain Management: An International Journal, 18 (6), pp. 618-629.

COOPER, M. C., LAMBERT, D. M., y PAGH, J. D. (1998). "Supply chain management: more than a new name for logistics". The International Journal of Logistics Management, 8 (1), pp. 1-14.

COUNCIL OF SUPPLY CHAIN MANAGEMENT PROFESSIONAL - CSCMP. Supply chain management definitions. Disponível em: <http://cscmp.org/ aboutcscmp/definitions.asp? $X X=1>$. Acesso em: 23 mar. 2012.

CHRISTOPHER, M. (2011). Logistics and supply chain management: creating value-adding networks, 4th ed., London: Financial Times/Prentice-Hall.

CROXTON, K. L., LAMBERT, D. M., GARCÍA-DASTUGUE, S. J., y ROGERS, D. S. (2002). "The demand management process". The International Journal of Logistics Management, 13 (2), pp. 51-66. 
CROXTON, K. L., LAMBERT, D. M., GARCÍA-DASTUGUE, S. J., y ROGERS, D. S. (2008). The demand management process. In: Lambert, D. M., Supply chain management: processes, partnerships, performance, 3rd ed, Florida: Supply Chain Management Institute.

DAUGHERTY, P. J. (2011). "Review of logistics and supply chain relationship literature and suggested research agenda". International Journal of Physical, Distribution \& Logistics Management, 41 (1), pp.1631.

ELLINGER, A. E., SHIN, H., NORTHINGTON, W. M., ADAMS, F. G., HOFMAN, D., y O'MARAH, K. (2012). "The influence of supply chain management competency on customer satisfaction and shareholder value". Supply Chain Management: An International Journal, 17 (3), pp. 249-262.

ESPER, T. L., ELLINGER, A. E., STANK, T. P., FLINT, D. J., y MOON, M. (2010). "Demand and supply integration: a conceptual framework of value creation through knowledge management". Academy of Marketing Science, 38 (1), pp. 5-18.

FABBE-COSTES, N., y JAHRE, M. (2008). "Supply chain integration and performance: a review of the evidence". The International Journal of Logistics Management, 19 (2), pp. 130-154.

FISHER, M. L. (1997). "What is the right supply chain for your product?". Harvard Business Review, 75 (2), pp. 105-166.

GIL, A. C. (2010). Como elaborar projetos de pesquisa, 5 ed., São Paulo: Atlas.

HILLETOFTH, P., ERICSSON, D., y CHRISTOPHER, M. (2009). "Demand chain management: a Swedish industrial case study". Industrial Management \& Data Systems, 109 (9), pp. 1179-1196.

HILLETOFTH, P. (2011). "Demand-supply chain management: industrial survival recipe for new decade". Industrial Management \& Data Systems, 111 (2), pp. 184-211.

JUTTNER, U., CHRISTOPHER, M., y BAKER, S. (2007). "Demand chain management-integrating marketing and supply chain management". Industrial Marketing Management, 36, pp. 377-392.

LAMBERT, D. M., y COOPER, M. C. (2000). "Issues in supply chain management". Industrial Marketing Management, 29 (1), pp. 65-83.
LAMBERT, D. M., GARCIA-DASTUGUE, S. J., y CROXTON, K. L. (2005). "An evaluation of process-oriented supply chain management frameworks". Journal of Business Logistics, 26 (1), pp. 25-51.

LAMBERT, D. M. (2008). Supply chain management. In: Lambert, D. M., Supply chain management: processes, partnerships, performance, 3rd ed., Florida: Supply Chain Management Institute.

LAU, K. H. (2012). "Demand management in downstream wholesale and retail distribution: a case study". Supply Chain Management: An International Journal, 17 (6), pp. 638-654.

LEE, H. L. (2002). "Aligning supply chain strategies with product uncertainties". California Management Review, 44 (3), pp. 105-119.

MELO, D. C., e ALCÂNTARA, R. L. C. (2011). "A gestão da demanda em cadeias de suprimentos: uma abordagem além da previsão de vendas". Gestão \& Produção, 18 (4), pp. 809-824.

MENTZER, J. T., WITT, W., KEEBLER, J. S., MIN, S., NIX, N. W., SMITH, C. D., y ZACHARIA, Z. G. (2001). "Defining supply chain management". Journal of Business Logistics, 22 (2), pp. 1-25.

MENTZER, J. T., y MOON, M. A. (2004). "Understanding demand". Supply Chain Management Review, 8 (4), pp. 38-45.

MENTZER, J. T., y MOON, M. A. (2005). Sales forecasting management: a demand management approach, Thousand Oaks: Sage.

PIRES, S. R. I. (2009). Gestão da cadeia de suprimentos: conceitos, estratégias, práticas e casos, 2 ed., São Paulo: Atlas.

RAINBIRD, M. (2004). "Demand and supply chains: the value catalyst". International Journal of Physical Distribution \& Logistics Management, 34 (3/4), pp. 230-250.

SANDERS, N. R., y RITZMAN, L. P. (2004). "Integrating judgmental and quantitative forecasts: methodologies for pooling marketing and operations information". International Journal of Operations \& Production Management, 24 (5), pp. 514-529.

SEURING, S. (2005). Case study research in supply chains: an outline and three examples. In: Kotzab, H.; Seuring, S.; Muller, M.; Reiner, G. (Eds.), Research methodologies in supply chain management, 
New York: Physica-Verlag.

STIGLITZ, J. E. (2007). Globalização: como dar certo, São Paulo: Companhia das Letras.

STRAUSS, A., e CORBIN, J. (2008). Pesquisa qualitativa: técnicas e procedimentos para o desenvolvimento de teoria fundamentada, 2 ed., Porto Alegre: Artmed.

VISWANADHAM, N., y GAONKAR, R. S. (2008). Risk management in global supply chain networks. In: Tang, C. S. (Ed.), Supply chain analysis, New York: Springer.

VOLUNTARY INTERINDUSTRY COMMERCE SOLUTIONS - VICS. Linking CPFR and S\&OP: a roadmap to integrated business planning 2010. Disponível em: <http://www.vics.org/docs/committees/cpfr/ CPFR_SOP_Guideline_Ver1.0Sep2010.pdf>. Acesso em: 15 abril de 2012.
VOSS, C. (2009). Case research in operations management. In: Karlson C. (Ed.), Researching operations management, New York: Routledge.

WALTERS, D., y RAINBIRS, M. (2004). "The demand chain as an integral component of the value chain". Journal of Consumer Marketing, 21 (7), pp. 465-475.

ZSIDISIN, G. A., ELLRAM, L. M., CARTER, J. R., y CAVINATO, J. L. (2004). "An analysis of supply risk assessment techniques". International Journal of Physical Distribution and Logistics Management, 34 (5), pp. 397-413.

ZOKAEI, K., y HINES, P. (2007). "Achieving consumer focus in supply chains". International Journal of Physical Distribution \& Logistics Management, 37 (3), pp. 223-247. 